ESAIM: COCV 27 (2021) E2

https://doi.org/10.1051/cocv/2021089
ESAIM: Control, Optimisation and Calculus of Variations

www.esaim-cocv.org

\title{
PREFACE
}

\section{A TRIBUTE TO PROFESSOR ENRIQUE ZUAZUA ON HIS 60TH BIRTHDAY}

In honor of Professor Enrique Zuazua, for his 60th birthday, we are very pleased to introduce this special issue of "ESAIM: Control, Optimisation and Calculus of Variations".

We have invited some of Enrique's friends and former students to contribute to this special issue. Many of them have collaborated with Enrique at some period of his career, and all of them want to show their appreciation and respect for his mathematical works. Totally, there are 38 papers finally accepted for publication after going through strict manuscript reviews and revision. These papers range over various fields such as control theory, partial differential equations, numerical analysis, shape optimization, applied mathematics in which Enrique has made important and seminal contributions. Professors Jean-Michel Coron and Alain Haraux have kindly written a survey of Enrique's career and mathematical works in the last thirty years.

To celebrate Enrique's 60th birthday, we intended to organize an international conference. Most of the contributors included here are expected to participate in this conference. Nevertheless, due to the epidemic situation of COVID-19, such a conference must be postponed in the future.

Finally, we would like to thank all the authors and reviewers for their high-quality critical contributions and valuable assistance that made the publication of this special issue possible.

September 2021

Guest Editors:

Giuseppe Buttazzo (Università di Pisa, Italy)

Eduardo Casas (University of Cantabria, Spain)

Luz de Teresa (Universidad Nacional Autónoma de México, Mexico)

Roland Glowinski (University of Houston, USA)

Günter Leugering (Friedrich-Alexander-Universität Erlangen-Nürnberg, Germany)

Emmanuel Trélat (Sorbonne Université, France)

Xu Zhang (Sichuan University, PR China) 